\title{
Prediction of Difficult Intubation with the Modified Mallampati and Upper Lip Bite Test: A Cross-Sectional Analysis
}

\author{
Muhammad Tayyeb ${ }^{1}$, Shah Faisal ${ }^{2}$, Abdullah ${ }^{*}$, Muhammad Ajmal ${ }^{1,4}$, Naqash Ahmad ${ }^{1}$, Muhammad \\ Arsalan ${ }^{1}$, Ayesha Jehad ${ }^{5}$, Bashir ul Haq ${ }^{1}$, Said Khitab Shah ${ }^{1}$ and Muhammad Qasim Jan ${ }^{6}$ \\ ${ }^{1}$ Department of Anaesthesia, Khyber Medical University, Peshawar, KPK, Pakistan \\ ${ }^{2}$ Department of Biotechnology, Bacha Khan University, Charsadda, KPK, Pakistan
}

${ }^{3}$ Department of Microbiology, Abdul Wali Khan University, Mardan, KPK, Pakistan

${ }^{4}$ Department of Anaesthesia, Hayatabad Medical Complex Peshawar, KPK, Pakistan

${ }^{5}$ College of Medical Technology, Medical Teaching Institutions Bacha Khan Medical College Mardan, Pakistan

${ }^{6}$ Department of Anaesthesia Qazi Hussain Ahmad Medical Complex, Pakistan

*Corresponding author: Abdullah, Department of Microbiology, Abdul Wali Khan University, Mardan, KPK, Pakistan, E-mail: abdul. 9353chd@gmail.com

Received date: May 23, 2020; Accepted date: May 27, 2020; Published date: June 5, 2020

Citation: Tayyeb M, Faisal S, Abdullah, Ajmal M, Ahmad N, Arsalan M, et al. (2020) Prediction of Difficult Intubation with the Modified Mallampati and Upper Lip Bite Test: A Cross-Sectional Analysis. J Biomed Sci Vol.9 No.2:5.

\section{Abstract}

Difficult intubation is a term used when insertion of the endotracheal tube with conventional laryngoscopy technique requires more than 10 minutes or greater than three attempts. This study sought to determine the predictive value of two commonly used tests; Mallampati test vs. Upper Lip Bite Test (ULBT). A cross-sectional study conducted on 196 patients aged 18-60 years in lady reading hospital Peshawar presented for elective surgeries planned for general anaesthesia and requiring endotracheal intubation were included during March 2018 to May 2018. Both tests (Mallampati and Upper lip bite test) were performed on each sample. In the total 196 participant $180(91.8 \%)$ were found easy cases and 16 (8.2\%) were difficult cases. Out of $16(8.2 \%)$ difficult cases 5 (31.3\%) difficult cases were underclass III Upper Lip Bite Test (ULBT) which are true positive. From Modified Mallampati Test 8 (50\%) were attributed to MMT class III which is $21.1 \%$ of total class III and 3 cases ( $18.8 \%$ of total difficult cases) with MMT class IV which is $75 \%$ of MMT class IV are both true positive. During anaesthesia and intubation, most common cause of death and brain damage is encounter because of difficult intubation. In this study, we have performed two tests i.e. ULBT and MMT on total of 196 patients, out of which 16 (8.2\%) were found difficult intubation which is in the range (0.5$17.5 \%)$ mention in the previous studies. The study has shown most of the difficult were predicted incorrectly. Most cases resulted in difficult intubation, which were predicted easily by two tests (Criteria set by Hoda et al.), so to only rely on ULBT and MMT for predictive measure is not standard.
Keywords: Modified mallampati test; Upper lip bite test; Difficult intubation; Anaesthesia; Laryngoscopy; Predictive test

Abbreviation: MMT: Modified Mallampati Test; ULBT: Upper Lip Bite Test

\section{Introduction}

The meaning of difficult intubation is 'the need of more attempts for intubation or taking more than 10 minutes during laryngoscopy or use of special equipment (instrument) for intubation or not viewed on laryngoscopy using Cormacklehane classification' The presence of only one will consider difficult intubation [1,2]. As reported the incidence of difficult endotracheal intubation is between $1.3 \%$ and $13 \%$ in patients undergoing general anaesthesia. Incidence of failed intubation varies from $0.05 \%$ to $0.35 \%$ whereas $0.01 \%-0.02 \%$ is incidence of inability to intubate and ventilate $[1,3]$. The most serious complication recorded by anaesthetist is a difficult airway (In which anaesthetist cannot deliver oxygen to the lungs). Around half of the cases are not recorded and are not predicted [4]. Many causes of difficult intubation, the important iatrogenic cause is an unexperienced and unprepared anaesthetist. Other cause due to anaesthetist includes inadequate preoperative assessment, equipment preparation, inexperienced and poor technique whereas equipment related causes is a malfunction of equipment and unavailability of proper equipment. Causes other than aesthetic and equipment are patient causes that may be acquired (reduced neck or jaw movement, Tumour, nerve palsy) or congenital (Down syndrome, Marfan syndrome, Treacher Collins syndrome) [5,6]. Difficult intubation leads to 
serious complications like pulmonary aspiration, hypoxia, laryngeal trauma, lip injury, and hemodynamic changes [7-10]. Mallampati test, interincisor distance, and thyromental distance are good preoperative test in prediction of difficult intubation [11], Proper preoperative assessment should be planned.

The purpose of the study is to determine the predictive value of two commonly used tests; Mallampati test vs. Upper Lip Bite Test (ULBT).

\section{Materials and Methods}

This is cross-sectional study conducted on 196 patients aged 18-60 years presented for elective surgeries planned for general aesthesia and requiring endotracheal intubation were included from March 2018 to May 2018. Edentulous and patients with limited cervical movement, severely short neck, stiff neck, and non-cooperative were excluded from study. Ethical approval was obtained from Lady Reading Hospital Peshawar Khyber Pakhtunkhwa and Hospital director for the data collection. The sampling of the patient was based on a convenience sampling technique. And both of the test i.e. upper lip bite test and Mallampati test were performed on these patients preoperatively after taking informed verbal consent. The proper standard technique was used for intubation and muscle relaxant are given. The data was collected in an organized datasheet. The observation recorded on the data sheets were analyzed by SPSS version 23. And data was represented in form of frequency table, percentages, bar charts, and pie charts.

\section{Results}

Both tests (Mallampati and Upper lip bite test) were performed on each sample. Out of 196 participants 67 (34.2\%) classified MMT class I, 87 (44.4\%) MMT class II, 38 (19.4\%) MMT class III and 4 (2\%) MMT class IV. And 69 (35.2\%) participants classified ULBT class I, 116 (59.2\%) ULBT class II, and 11 (5.6\%) ULBT class III. In the total 196 participants 180 $(91.8 \%)$ were found easy cases and 16 (8.2\%) were difficult cases as shown in Table 1.

Table 1: Frequency (and percentage) of MMT and ULBT classes and their contribution (in percentage) on account of difficult and easy intubation within their respective MMT and ULBT classes.

\begin{tabular}{|c|c|c|c|c|c|c|}
\hline \multirow[t]{3}{*}{ Classes } & \multirow{2}{*}{$\begin{array}{l}\begin{array}{l}\text { Modified } \\
\text { (MMT) }\end{array} \\
\begin{array}{c}\text { Difficult } \\
\text { intubation }\end{array}\end{array}$} & Mallampati & Test & \multicolumn{3}{|c|}{ Upper Lip Bite Test (ULBT) } \\
\hline & & $\begin{array}{c}\text { Easy } \\
\text { intubation }\end{array}$ & Total & $\begin{array}{l}\text { Difficult } \\
\text { intubation }\end{array}$ & $\begin{array}{l}\text { Easy } \\
\text { intubation }\end{array}$ & Total \\
\hline & n (\%) & n (\%) & & n (\%) & n (\%) & \\
\hline $\begin{array}{l}\text { Class } \\
\text { I }\end{array}$ & $2(3.0 \%)$ & $\begin{array}{l}65 \\
(97.0 \%)\end{array}$ & 67 & $1(1.4 \%)$ & $\begin{array}{l}68 \\
(98.6 \%)\end{array}$ & 69 \\
\hline $\begin{array}{l}\text { Class } \\
\text { II }\end{array}$ & $3(3.4 \%)$ & $\begin{array}{l}84 \\
(96.6 \%)\end{array}$ & 87 & $\begin{array}{l}10 \\
(8.6 \%)\end{array}$ & $\begin{array}{l}106 \\
(91.4 \%)\end{array}$ & 116 \\
\hline
\end{tabular}

\begin{tabular}{|l|l|l|l|l|l|l|}
\hline $\begin{array}{l}\text { Class } \\
\text { III }\end{array}$ & $\begin{array}{l}8 \\
(21.1 \%)\end{array}$ & $\begin{array}{l}30 \\
(78.9 \%)\end{array}$ & 38 & $\begin{array}{l}5 \\
(45.5 \%)\end{array}$ & $\begin{array}{l}6 \\
(54.5 \%)\end{array}$ & 11 \\
\hline $\begin{array}{l}\text { Class } \\
\text { IV }\end{array}$ & $\begin{array}{l}3 \\
(75.0 \%)\end{array}$ & $\begin{array}{l}1 \\
(25.0 \%)\end{array}$ & 4 & & & \\
\hline $\begin{array}{l}\text { Total } \\
\text { (out } \\
\text { of } \\
\mathbf{1 9 6 )}\end{array}$ & 16 & $\begin{array}{l}180 \\
(91.8 \%)\end{array}$ & $\begin{array}{l}19 \\
6\end{array}$ & $\begin{array}{l}16 \\
(8.2 \%)\end{array}$ & $\begin{array}{l}180 \\
(91.8 \%)\end{array}$ & $\begin{array}{l}19 \\
6\end{array}$ \\
\hline
\end{tabular}

Of the total 196, $94(48 \%)$ and $102(52 \%)$ were male and female. 8 males (8.5\% of 94 males) and 8 (7.8\% of total 102 females) were found difficult to intubate which is $50,50 \%$ of the total 16 difficult cases.

Out of 16 (8.2\%) difficult cases 5 (31.3\%) difficult cases are coming under class III Upper Lip Bite Tests (ULBT) which are true positive. From Modified Mallampati Test 8 (50\%) were attribute to MMT class III which is $21.1 \%$ of total class III and 3 cases ( $18.8 \%$ of total difficult cases) with MMT class IV which is $75 \%$ of MMT class IV are both true positive as shown in Tables 2 and 3.

Table 2: Statistical terms used for upper lip bite as predicting tests, and its value accordance to difficult intubation.

\begin{tabular}{|c|c|c|c|c|c|c|}
\hline \multicolumn{2}{|l|}{ Predictive test } & \multicolumn{5}{|c|}{ Statistical test } \\
\hline & & $\begin{array}{c}\text { True } \\
\text { Positive }\end{array}$ & $\begin{array}{c}\text { False } \\
\text { Positive }\end{array}$ & $\begin{array}{l}\text { True } \\
\text { Negative }\end{array}$ & $\begin{array}{l}\text { False } \\
\text { Negative }\end{array}$ & Total \\
\hline & & n (\%) & n (\%) & n (\%) & n (\%) & n (\%) \\
\hline \multirow{3}{*}{$\begin{array}{l}\text { Uppe lip Bite } \\
\text { Test } \\
\text { Classifications }\end{array}$} & $\begin{array}{c}\text { class } \\
\text { I }\end{array}$ & --- & --- & $\begin{array}{l}68 \\
(34.7 \%)\end{array}$ & $\begin{array}{l}01 \\
(0.5 \%)\end{array}$ & $\begin{array}{c}69 \\
(35.2 \%)\end{array}$ \\
\hline & $\begin{array}{c}\text { class } \\
\text { II }\end{array}$ & --- & --- & $\begin{array}{l}106 \\
(54.1 \%)\end{array}$ & $\begin{array}{l}10 \\
(5.1 \%)\end{array}$ & $\begin{array}{l}116 \\
(59.2 \\
\%)\end{array}$ \\
\hline & $\begin{array}{c}\text { class } \\
\text { III }\end{array}$ & $\begin{array}{l}05 \\
(2.6 \%)\end{array}$ & $\begin{array}{l}06 \\
(3.1 \%)\end{array}$ & --- & --- & $\begin{array}{l}11 \\
(5.6 \%)\end{array}$ \\
\hline $\begin{array}{l}\text { Total among } \\
\text { ULBT } \\
\text { classes }\end{array}$ & & $\begin{array}{l}05 \\
(2.6 \%)\end{array}$ & $\begin{array}{l}06 \\
(3.1 \%)\end{array}$ & $\begin{array}{l}174 \\
(88.8 \%)\end{array}$ & $\begin{array}{l}11 \\
(5.6 \%)\end{array}$ & $\begin{array}{c}196 \\
(100 \%)\end{array}$ \\
\hline
\end{tabular}

Table 3: Predictive Values for the MMT classes predict the Occurrence accordance to difficult intubation in MMT classification.

\begin{tabular}{|c|c|c|c|c|c|c|}
\hline \multirow{2}{*}{\multicolumn{2}{|c|}{ Predictive test }} & \multicolumn{5}{|c|}{ Statistical test } \\
\hline & & $\begin{array}{c}\text { True } \\
\text { Positive }\end{array}$ & $\begin{array}{l}\text { False } \\
\text { Positive }\end{array}$ & $\begin{array}{l}\text { True } \\
\text { Negative }\end{array}$ & $\begin{array}{c}\text { False } \\
\text { Negative }\end{array}$ & Total \\
\hline & & n (\%) & n (\%) & n (\%) & n (\%) & \\
\hline \multirow{2}{*}{$\begin{array}{l}\text { Modified } \\
\text { Mallampa } \\
\text { ti classes }\end{array}$} & $\begin{array}{c}\text { class } \\
1\end{array}$ & --- & --- & $\begin{array}{l}65 \\
(33.2 \%)\end{array}$ & $\begin{array}{l}2 \\
(1.0 \%)\end{array}$ & $\begin{array}{c}67 \\
(34.2 \%)\end{array}$ \\
\hline & $\begin{array}{c}\text { class } \\
\text { II }\end{array}$ & --- & --- & $3(1.5 \%)$ & $\begin{array}{l}84 \\
(42.9 \%)\end{array}$ & $\begin{array}{c}87 \\
(44.4 \%)\end{array}$ \\
\hline
\end{tabular}




\begin{tabular}{|c|c|c|c|c|c|c|}
\hline & $\begin{array}{c}\text { class } \\
\text { III }\end{array}$ & $\begin{array}{l}8 \\
(4.1 \%)\end{array}$ & $\begin{array}{c}30 \\
(15.3 \%)\end{array}$ & --- & -- & $\begin{array}{c}38 \\
(19.4 \%)\end{array}$ \\
\hline & $\begin{array}{c}\text { class } \\
\text { IV }\end{array}$ & $\begin{array}{l}3 \\
(1.5 \%)\end{array}$ & $\begin{array}{l}1 \\
(0.5 \%)\end{array}$ & --- & --- & $\begin{array}{l}4 \\
(2.0 \%)\end{array}$ \\
\hline $\begin{array}{l}\text { Total } \\
\text { among } \\
\text { MMT } \\
\text { classes }\end{array}$ & & $\begin{array}{l}11 \\
(5.6 \%)\end{array}$ & $\begin{array}{c}31 \\
(15.8 \%)\end{array}$ & $\begin{array}{l}68 \\
(34.7 \%)\end{array}$ & $\begin{array}{l}86 \\
(43.9 \%)\end{array}$ & $\begin{array}{l}196 \\
(100 \%)\end{array}$ \\
\hline
\end{tabular}

Out of total 16 difficult cases, ULBT class I has 1 (6.3\% cases) that is $1.4 \%$ of total 69 ULBT class I and ULBT class II had 10 (62.5\% out of 16 ) cases that is $8.6 \%$ of total 116 ULBT class II, both of which are false negative. And out of 180 easy cases 6 (3.3\%) cases in ULBT class III as false positive, which accounts for 54.5\% among 11 ULBT class III Tables 2 and 4.

Table 4: Statistical terms and definitions.

\begin{tabular}{|l|l|}
\hline $\begin{array}{l}\text { True } \\
\text { Positive }\end{array}$ & $\begin{array}{l}\text { Intubation that is predicted to be difficultand results in difficult } \\
\text { as well }\end{array}$ \\
\hline $\begin{array}{l}\text { False } \\
\text { Positive }\end{array}$ & Intubation that is predicted to be difficult and turns out easy \\
\hline $\begin{array}{l}\text { True } \\
\text { Negative }\end{array}$ & $\begin{array}{l}\text { Intubation that is predicted to be easy and results in easy as } \\
\text { well. }\end{array}$ \\
\hline $\begin{array}{l}\text { False } \\
\text { negative }\end{array}$ & Intubation that is predicted to be easy and turns out difficult. \\
\hline
\end{tabular}

\section{Discussion}

During anaesthesia and intubation, most common cause of death and brain damage is encounter because of difficult intubation [1,12-16]. Difficult intubation reported by many studies is in the range of $0.5 \%-17.5 \%$. [1,17-20]. In this study, we have performed two tests i.e. ULBT and MMT on a total of 196 patients, out of which 16 (8.2\%) were found difficult intubation which is in the range mention in the previous studies. As none of the anatomical factors can predict difficult intubation with $100 \%$ accuracy, so predictive test can be considered unreliable. Different reference standards utilized for difficult intubation such variations happen. The reference standard used for assessing difficult intubation is Cormack and Lehane intubation grade, $[1,21]$ the total attempts on laryngoscopy, [1,22], and the utilization of BURP (Backward Upward Rightward Pressure) maneuver [1,17]. 05 (2.6\%) of ULBT classes were found in our study to be true positive which are comparable to L. Eberhart et al. [20] and Khan et al. [17] findings, i.e. $3.3 \%$ and $4.3 \%$ respectively and is much less than M. Ali et al. [1] results that is $15.1 \%$. From Mallampati test we got $11(5.6 \%)$ of cases as true positive which is comparable to Khan et al. [17] and M. Ali et al. [1] findings i.e. 4.7\% and 3.4\% respectively. and is less than L. Eberhart et al. [20] which is 8.3\%. Of total ULBT class, $88.8 \%$ were found to be true negative that is higher than the previous study by L. Eberhart et al. [20], Khan et al. [17] and M. Ali et al. [1] which are $83.4 \%, 83.7 \%$, and $76.9 \%$ respectively. And 68 (34.7\%) were found true negative among MMT classes which is less than results of L. Eberhart et al. [20], Khan et al. [17] and M. Ali et al. [1] which are $53.7 \%, 63.0 \%$ and $75.9 \%$ respectively.

False-positive cases found ULBT classes was 06 (3.1\%), less than the finding of L. Eberhart et al. [20], Khan et al. [17] and M. Ali et al. [1] which are $6.6 \%, 10.7 \%$, and $5.9 \%$ respectively. Whereas false positive in MMT classes were 31 (15.8\%), much less than the finding of L. Eberhart et al. [20] and Khan et al. [17] which are $34.4 \%$ and $31.3 \%$ and are greater than that of M. Ali et al. [1], which are $6.8 \%$ respectively. False-positive were 11 (5.6\%) among ULBT classes which is less than L. Eberhart et al. [20] study result that is $8.5 \%$ and is greater than both Khan et al. [17] and M. Ali et al. [1] study results that are $1.3 \%$ and $2.1 \%$ respectively and $86(43.9 \%)$ cases of falsepositive in MMT classes, that is much greater than previous studies i.e. L. Eberhart et al. [20], Khan et al. [17] and M. Ali et al. [1], whose finding are $3.5 \%, 1.0 \%$, and $13.9 \%$.

\section{Conclusion}

The study has shown most of the difficulties were predicted incorrectly. Most cases resulted in difficult intubation, which was predicted easily by two tests (Criteria set by Hoda et al). MMT and ULBT are easy to perform except few patients and are advice to be done but rely on only on these two don't always predict difficult intubation.

\section{Acknowledgment}

We are grateful to Lady Reading Hospital, Peshawar, Khyber Pakhtunkhwa, Pakistan for providing research facilities.

\section{Funding Source}

Not applicable

\section{Conflict of Interest}

The authors declare no conflict of interest.

\section{Author's Contributions}

Tayyeb M contributed majorly to this research work his contributions are; performed research work, conceptualization, idea, and writing the main manuscript draft. Faisal $\mathrm{S}$ contributed to the Figures and tables. Abdullah contributed to the formatting of the main manuscript. Ajmal M, Ahmad N, Arsalan M, Jehad A, Haq BU, Shah SK, Jan MQ help in proofreading.

\section{Reference}

1. Ali MA, Qamar-ul-Hoda M, Samad K (2012) Comparison of upper lip bite test with Mallampati test in the prediction of difficult intubation at a tertiary care hospital of Pakistan. J Pak Med Assoc 62: 1012-1015. 
2. Yentis SM (2002) Predicting difficult intubation worthwhile exercises or pointless ritual. Anaesthesia 57: 105-109.

3. Mort TC (2004) Emergency tracheal intubation: Complications associated with repeated laryngoscopic attempts. Anesth Analg 99: 607-613.

4. Paix AD, Williamson JA, Runciman WB (2005) Crisis management during anesthesia: difficult intubation. $\mathrm{Br}$ Med J 160: 1-7.

5. Aitkenhead A, Smith G (2013) The practical conduct of anaesthesia. Smith and Aitken head's Textbook of Anaesthesia 6th Ed, pp: 454-455

6. Orfanos JG, Quereshy FA (2010) Causes of the difficult airway. Atlas Oral Maxil Surg Clin Nor Amer 18: 1-9.

7. Apfelbaum JL, Hagberg CA, Caplan RA, Blitt CD, Connis RT, et al. (2013) Practice guidelines for management of the difficult airway an updated report by the American Society of Anaesthesiologists task force on management of the difficult airway. Anaesthesiol J Amer Soc Anaesthesiolog 118: 251-270.

8. Hagberg C, Georgi R, Krier C (2005) Complications of managing the airway. Best Pract Res Clin Anaesthesiol 19: 641-659.

9. Pacheco-Lopez PC, Berkow LC, Hillel AT, Akst LM (2014) Complications of airway management. Respir Care 59: 1006-1021.

10. Cook TM, Macdougall-Davis SR (2012) Complications and failure of airway management. Br J Anaesth 109: 68-85.

11. Tamire T, Demelash H, Admasu W (2019) Predictive values of preoperative tests for difficult laryngoscopy and intubation in adult patients at tikur anbessa specialized hospital. Anesthesiol Res Pract 2019: e-1790413.

12. Wong S, Hung C (1999) Prevalence and prediction of difficult intubation in Chinese women. Anaesth Intensive Care 27: 49-52.

13. Hung O, Mills J (2000) Predictions and clinical decisions: a fine balance. Can J Anaesth 47: 721-724.
14. Siddiqui R, Kazi W (2005) Predicting difficult intubation, a comparison between Mallampati classification and Wilson Risk-Sum. J Coll Physician Surg Pak 15: 253-256.

15. Turkan S, Ates Y, Cuhruk H, Tekdemir I (2002) Should we re-evaluate the variables for predicting the difficult airway in anaesthesiology? Anesth Analg 94: 1340-1344.

16. Hilditch WG, Kopka A, Crawfordet, Asbury AJ (2004) Interobserver reliability between a nurse and anaesthetist of tests used for predicting difficult tracheal intubation. Anaesthesia 59: 881-884

17. Khan ZH, Ebrahimkhani E (2003) A Comparison of the upper lip bite test (a simple new technique) with modified mallampati classification in predicting difficulty in endotracheal intubation: A prospective blinded study. Anesth Analg 96: 595-599.

18. Mishra S, Bhat R, Nagappa M, Badhe A (2008) Comparison of upper lip bite test with modified Mallampati classification for prediction of difficult obstetric intubation. Int J Anaesthesiol 19: 5-9.

19. Karci A, Karagöz S, Girgin P, Bozdogan D (2011) Comparison of modified Mallampati classification, upper lip bite test and neck circumference in prediction of difficult intubation: 19AP5-5. Eur J Anaesthesiol 28: 236.

20. Eberhart LHJ, Arndt C, Cierpka T, Schwanekamp J, Wulf H, et al. (2005) The reliability and validity of the Upper Lip Bite test compared with the Mallampa classicaon to predict dicult laryngoscopy: An external prospecve evaluaon. Anesth Analg 101: 284-289.

21. Khan ZH, Maleki A, Makarem J, Mohammadi M, Khan RH (2011) A comparison of the upper lip bite test with hyomental/thyrosternal distances and mandible length in predicng diculty in intubaon: A prospecve study. Ind J Anesth 55: 43-46.

22. Brodsky JB, Lemmens HJ, Brock Utne JG, Vierre MSL (2002) Morbid obesity and tracheal intubaon. Anesth Analg 94: 732-736. 